\title{
Immuno-PET of the Hepatocyte Growth Factor Receptor Met Using the 1-Armed Antibody Onartuzumab
}

\author{
Elaine M. Jagoda ${ }^{1}$, Lixin Lang ${ }^{2}$, Veerendra Bhadrasetty ${ }^{1}$, Stephanie Histed ${ }^{1}$, Mark Williams ${ }^{1}$, Gabriela Kramer-Marek ${ }^{3}$, \\ Esther Mena ${ }^{1}$, Lauren Rosenblum ${ }^{1}$, Jan Marik ${ }^{4}$, Jeff N. Tinianow ${ }^{4}$, Mark Merchant ${ }^{4}$, Lawrence Szajek ${ }^{5}$, Chang Paik ${ }^{6}$, \\ Fabiola Cecchi ${ }^{7}$, Kristen Raffensperger ${ }^{7}$, Joe-Marie Jose-Dizon ${ }^{7}$, Donald P. Bottaro ${ }^{7}$, and Peter Choyke ${ }^{1}$ \\ ${ }^{1}$ Molecular Imaging Program, National Cancer Institute, National Institutes of Health, Bethesda, Maryland; ${ }^{2}$ Laboratory of \\ Molecular Imaging and Nanomedicine, National Institute of Biomedical Imaging and Bioengineering, National Institutes of Health, \\ Bethesda, Maryland; ${ }^{3}$ Radiation Oncology Branch, National Cancer Institute, National Institutes of Health, Bethesda, Maryland; \\ ${ }^{4}$ Genentech, Inc., South San Francisco, California; ${ }^{5}$ PET Department, Clinical Center, National Institutes of Health, Bethesda, \\ Maryland; ${ }^{6}$ Department of Nuclear Medicine, Clinical Center, National Institutes of Health, Bethesda, Maryland; and ${ }^{7}$ Urologic \\ Oncology Branch, National Cancer Institute, Bethesda, Maryland
}

The overexpression and overactivation of hepatocyte growth factor receptor (Met) in various cancers has been linked to increased proliferation, progression to metastatic disease, and drug resistance. Developing a PET agent to assess Met expression would aid in the diagnosis and monitoring of responses to Met-targeted therapies. In these studies, onartuzumab, the experimental therapeutic 1-armed monoclonal antibody, was radiolabeled with ${ }^{76} \mathrm{Br}$ or ${ }^{89} \mathrm{Zr}$ and evaluated as an imaging agent in Met-expressing cell lines and mouse xenografts. Methods: ${ }^{89} \mathrm{Zr}$-desferrioxamine (df)-onartuzumab was synthesized using a df-conjugate; ${ }^{76} \mathrm{Br}$-onartuzumab was labeled directly. Metbinding studies were performed using the human tumorderived cell lines MKN-45, SNU-16, and U87-MG, which have relatively high, moderate, and low levels of Met, respectively. Biodistribution and small-animal PET studies were performed in MKN-45 and U87-MG xenografts. Results: ${ }^{76} \mathrm{Br}$-onartuzumab and ${ }^{89} \mathrm{Zr}$-df-onartuzumab exhibited specific, high-affinity Met binding (in the nanomolar range) that was concordant with established Met expression levels. In MKN-45 (gastric carcinoma) xenografts, both tracers cleared slowly from nontarget tissues, with the highest uptake in tumor, blood, kidneys, and lungs. ${ }^{76} \mathrm{Br}$-onartuzumab MKN-45 tumor uptake remained relatively constant from $18 \mathrm{~h}$ (5 percentage injected dose per gram of tissue [\%ID/g]) to $48 \mathrm{~h}(3 \% \mathrm{ID} / \mathrm{g})$ and exhibited tumor-to-muscle ratios ranging from $4: 1$ to $6: 1$. In contrast, ${ }^{89} \mathrm{Zr}$-df-onartuzumab MKN-45 tumor uptake continued to accumulate from $18 \mathrm{~h}$ (10\% ID/g) to $120 \mathrm{~h}(23 \% \mathrm{ID} / \mathrm{g})$, attaining tumor-to-muscle ratios ranging from $20: 1$ to $27: 1$. MKN-45 tumors were easily visualized in imaging studies with both tracers at $18 \mathrm{~h}$, but after $48 \mathrm{~h}{ }^{89} \mathrm{Zr}$-dfonartuzumab image quality improved, with at least 2-fold-greater tumor uptake than nontarget tissues. MKN-45 tumor uptake for both tracers correlated significantly with tumor mass and Met expression and was not affected by the presence of plasma shed Met. Conclusion: ${ }^{89} \mathrm{Zr}$-df-onartuzumab and ${ }^{76} \mathrm{Br}$-onartuzumab specifically targeted Met in vitro and in vivo; ${ }^{89} \mathrm{Zr}$-df-onartuzumab

Received Dec. 26, 2011; revision accepted May 21, 2012.

For correspondence or reprints contact: Elaine M. Jagoda, Molecular Imaging Program, National Cancer Institute, 10 Center Dr., Bldg. 10/Room B3B69,

Bethesda, MD 20892-1088.

E-mail: ejagoda@mail.nih.gov

Published online Aug. 23, 2012.

COPYRIGHT (C) 2012 by the Society of Nuclear Medicine and Molecular Imaging, Inc. achieved higher tumor uptake and tumor-to-muscle ratios than ${ }^{76} \mathrm{Br}$-onartuzumab at later times, suggesting that ${ }^{89} \mathrm{Zr}$-dfonartuzumab would be better suited to image Met for diagnostic and prognostic purposes.

Key Words: immuno-PET imaging; Met receptor; ${ }^{76} \mathrm{Br}-$ onartuzumab; ${ }^{89} \mathrm{Zr}$-df-onartuzumab; MetMAb

J Nucl Med 2012; 53:1592-1600

DOI: 10.2967/jnumed.111.102293

$\mathbf{T}$

he hepatocyte growth factor receptor tyrosine kinase (Met) is overexpressed or aberrantly activated in a variety of cancers, including gastric, colon, bladder, breast, liver, lungs, pancreatic, esophageal, prostate, and cervical (1). Met gene amplification, mutation, or overexpression in cancer results in increased proliferation, inhibition of apoptosis, tumor angiogenesis, and progression to metastatic disease $(1,2)$. Met amplification or overexpression also has been associated with poor prognosis and drug resistance (3). Together, these attributes suggest that the ability to determine changes in Met expression in real time with a Met-targeted imaging agent could prove invaluable for diagnosis, patient selection, monitoring of disease progression, and identification of instances when a Met-targeted therapeutic might be beneficial for the patient.

Onartuzumab (MetMAb; Genentech (4)), a Met-selective humanized 1-armed monoclonal antibody ( $\sim 99,000 \mathrm{kDa}$; derived from $\mathrm{IgG1}$, monoclonal antibody 5D5) possessing nanomolar affinity for Met, has displayed antiproliferative, antiangiogenic, and proapoptotic properties in mouse tumor models, resulting in inhibition of tumor growth $(4,5)$. Currently, onartuzumab has been studied in phase I-III clinical trials in which it was well tolerated and in which non-small cell lung cancer patients with Met-positive tumors showed improved survival (6). The therapeutic effect of onartuzumab results from competitive antagonism of hepatocyte growth factor binding to the Met extracellular domain, thereby preventing pathway ac- 
tivation (4). Although high affinity and target specificity of onartuzumab are desirable attributes required for a PET agent, the slow in vivo clearance of this large protein from the circulation and nontarget tissues would require the use of longer-lived PET radionuclides, thus ensuring enough time for clearance of nontarget radioactivity but leaving sufficient radioactivity in target regions for detection with $\operatorname{PET}(7,8)$. In a previous study by Perk et al. (9), the Met-specific whole monoclonal antibody DN30 $(\sim 150 \mathrm{kDa})$ labeled with the longer-lived radionuclide ${ }^{89} \mathrm{Zr}\left(t_{1 / 2}=78.4 \mathrm{~h}\right)$ provided semiquantitative images of human Met-expressing tumors in mouse xenografts, proving the utility of longer-lived radionuclides in compensating for the slow pharmacokinetics of large-molecular-weight proteins. In addition, the radiolabeled DN30 tumor uptake corresponded to Met expression levels and represented bivalent binding to Met. Although this bivalent binding was found to result in receptor dimerization and phosphorylation, the ensuing biologic responses were only partial; hence, DN30 has been termed a partial agonist. In contrast, onartuzumab is a pure antagonist capable of only monovalent binding to the receptor, representing quantitatively a $1: 1$ molar binding ratio $(4,10)$.

For these studies, we have radiolabeled onartuzumab with the longer-lived PET radionuclides ${ }^{76} \mathrm{Br}\left(t_{1 / 2}=16.2 \mathrm{~h}\right)$ or ${ }^{89} \mathrm{Zr}$ and evaluated its imaging potential in vitro and in vivo. ${ }^{76} \mathrm{Br}$ was initially selected because it afforded a direct labeling method with little modification of the antibody whereas ${ }^{89} \mathrm{Zr}$ requires a chelate for conjugation to the antibody. The cell lines MKN-45 (human gastric carcinoma), SNU-16 (human gastric carcinoma), and U87-MG (human glioblastoma)—which have high, moderate, and low Met concentrations, respectively-were used for binding studies to determine the biologic activity (percentage immunoreactivity) and the affinity (dissociation constant, $\mathrm{K}_{\mathrm{d}}$ ) of ${ }^{76} \mathrm{Br}$-onartuzumab and ${ }^{89} \mathrm{Zr}$-desferrioxamine (df)-onartuzumab and in mouse xenograft models to determine the in vivo biodistribution and imaging characteristics of ${ }^{76} \mathrm{Br}$-onartuzumab and ${ }^{89} \mathrm{Zr}$-df-onartuzumab $(11,12)$. Additionally, plasma and tumor samples were collected to evaluate human shed Met ectodomain and tumor Met abundance (Met receptor concentration or density), respectively, using immunoassays $(11,13)$. Met sheds its ectodomain (shed Met), a process in which transmembrane portions of the receptor are proteolytically cleaved and released into the biologic circulation. The concentration of shed Met in plasma and urine was found to correlate with tumor burden in mouse xenografts (11). Because shed Met may interfere with binding of radiolabeled onartuzumab, we investigated the relationship between shed Met, tumor Met abundance, and tumor mass. Collectively, these studies demonstrate the potential utility of PET-labeled onartuzumab.

\section{MATERIALS AND METHODS}

\section{Cell Lines and Reagents}

Cell lines were grown at $37^{\circ} \mathrm{C}$ and $5 \% \mathrm{CO}_{2}$ using RPMI 1640 for MKN-45; RPMI 1640, $10 \mathrm{mM} \mathrm{N}$-(2-hydroxyethyl)piperazine-
$N^{\prime}$-(2-ethanesulfonic acid), $1 \mathrm{mM}$ sodium pyruvate, glucose $(4,500 \mathrm{mg} / \mathrm{L})$, and sodium bicarbonate $(1,500 \mathrm{mg} / \mathrm{L})$ for SNU-16; or Dulbecco modified Eagle medium, $0.1 \mathrm{mM}$ nonessential amino acids, and $1 \mathrm{mM}$ sodium pyruvate for U87-MG. All media were supplemented with $10 \%$ fetal bovine serum, $2 \mathrm{mM}$ L-glutamine, and penicillin-streptomycin-amphotericin B.

Onartuzumab that was conjugated to df through an isothiocyanate linker, $p$-isothiocyanatobenzyl-df-onartuzumab, was provided by Jeffrey Tinianow (Genentech), who used a conjugation procedure previously described $(14,15)$.

\section{Radiosynthesis of ${ }^{76} \mathrm{Br}$-Onartuzumab and ${ }^{89} \mathrm{Zr}$-df-Onartuzumab}

The radiosynthesis of ${ }^{76} \mathrm{Br}$-onartuzumab was accomplished by direct bromination of available tyrosine residues. Briefly, ${ }^{76} \mathrm{Br}$ was produced from a ${ }^{75} \mathrm{As}\left({ }^{3} \mathrm{He}, 2 \mathrm{n}\right)-{ }^{76} \mathrm{Br}$ reaction and isolated from the solid target by oxidation (16). The radiobrominations were performed with onartuzumab $(300 \mu \mathrm{g})$ in $\mathrm{pH} 6.4$ phosphate buffer and aqueous ammonium ${ }^{76} \mathrm{Br}$-bromide $(74-185 \mathrm{MBq})$ in the presence of chloramine-T for $5 \mathrm{~min}$. The product was purified by size-exclusion high-performance liquid chromatography (quadruple time-of-flight mass spectrometry [Waters] coupled with an ultra performance liquid chromatography Acquity system [Waters]). Typical radiolabeling yield was $45 \% \pm 4.4 \%(n=10)$, with a specific activity (at the end of synthesis) of $0.118 \pm 0.067 \mathrm{MBq} / \mu \mathrm{g}(n=10)$.

The radiosynthesis of ${ }^{89} \mathrm{Zr}$-df-onartuzumab was accomplished using a modified method of Perk et al. (14). Briefly, purified ${ }^{89} \mathrm{Zr}$ (IV) in $1 \mathrm{M}$ oxalic acid (74-148 MBq) was neutralized with $\mathrm{Na}_{2} \mathrm{CO}_{3}$ (2 M) and $N$-(2-hydroxyethyl)piperazine- $N^{\prime}$-(2-ethanesulfonic acid) (0.5 M, pH 7.0) and reacted with df-onartuzumab $(14.7 \mathrm{mg} / \mathrm{mL}, 0.25$ $\left.\mathrm{M} \mathrm{C}_{2} \mathrm{H}_{3} \mathrm{NaO}_{2}, \mathrm{pH} 5.5\right)$ in ascorbic or gentisic acid $(5 \mathrm{mg} / \mathrm{mL})$ or $1 \%$ bovine serum albumin for $1 \mathrm{~h}$. Typical labeling yields determined by size-exclusion high-performance liquid chromatography with ultraviolet monitoring were greater than $90 \%$, with specific activities (at the end of synthesis) ranging from 0.037 to $0.185 \mathrm{MBq} / \mu \mathrm{g}$.

\section{In Vitro Studies}

Saturation binding studies were done to determine the $\mathrm{K}_{\mathrm{d}}$ and concentration of Met $\left(\mathrm{B}_{\text {max }}\right)$ using plated MKN-45 cells $\left(2 \times 10^{5}\right.$ cells per well) and SNU-16 or U87-MG cells in tubes $\left(2-10 \times 10^{5}\right.$ cells per tube) to which increasing concentrations of radiolabeled onartuzumab $(0.2-$ $10 \mathrm{nM}$ ) were added; nonspecific binding was determined by adding unlabeled onartuzumab $\left(10^{-6.3} \mathrm{M}\right)$ to another set of duplicates. After incubation for $2 \mathrm{~h}\left(4^{\circ} \mathrm{C}\right)$, the cell-bound radiolabeled onartuzumab was separated from free onartuzumab. Plated cells were washed (phosphate-buffered saline), treated with trypsin, and collected in vials. Cells in tubes were centrifuged and washed twice (phosphate-buffered saline), and the cell-bound radioactivity for these samples was determined by $\gamma$-counting (2480 Wizard3; Perkin Elmer). The $\mathrm{K}_{\mathrm{d}}$ and $\mathrm{B}_{\max }$ were determined from at least 6-8 concentrations of radiolabeled onartuzumab and analyzed using nonlinear regression curve fits (1-site binding hyperbola) (Prism, version 3.02 for Windows [Microsoft]; GraphPad Software).

One of 2 methods was used to determine the immunoreactive fractions or biologic specific activity of the radiolabeled onartuzumab as previously described. Briefly, we used a modified method described by Lindmo et al. $(17,18)$ in which the immunoreactivity was calculated by extrapolation to infinite antigen excess conditions. Alternatively, we used a modification of the specific activity determination by self-displacement technique described by Morris (19), which is derived from a radiolabeled onartuzumab saturation curve and competition curve with unlabeled onartuzumab. 


\section{Mouse Tumor Models}

Athymic female nude mice (Ncr-nu/nu; National Cancer Institute) were injected subcutaneously in the right thigh with MKN-45 or U87-MG cells $\left(5-8 \times 10^{6}\right)$ in phosphate-buffered saline:30\% Matrigel (BD Biosciences). All animal studies were performed in accordance with the Guidelines for the Care and Use of Laboratory Animals (20) (National Institutes of Health) using protocols approved by the Institutional Animal Care and Use Committee.

\section{Biodistribution Studies}

Nude or tumor (50-1,000 mg)-bearing mice were injected while awake via the tail (intravenously) with either ${ }^{76} \mathrm{Br}$-onartuzumab (0.185-0.74 MBq, 2-5 $\mu \mathrm{g})$, ${ }^{89} \mathrm{Zr}$-df-onartuzumab (0.37-1.85 MBq, 3-46 $\mu \mathrm{g}$ ), or ${ }^{89} \mathrm{Zr}$-oxalate (neutralized) (0.185-0.74 MBq) and euthanized $\left(\mathrm{CO}_{2}\right.$ inhalation) at selected times. Blood (cardiac puncture) and tissues were excised from each animal and weighed, and the radioactive concentration was determined (2480 Wizard3). The radioactivity in the blood and each tissue was expressed as percentage injected dose per gram of tissue (\%ID/g) normalized to a 20 -g mouse: $100 \times\left(\left[\mathrm{cpm}_{\text {tissue }}\right] /\left[\mathrm{cpm}_{\text {injected dose }}\right] \times[\right.$ tissue weight $\left.(\mathrm{g})]\right) \times$ ([body weight]/[20]). Immediately after counting, tumor samples were fast-frozen and stored at $-70^{\circ} \mathrm{C}$ for determination of Met content. An additional blood sample was collected in ethylenediaminetetraacetic acid-coated tubes, and after being centrifuged, the separated plasma samples were fast-frozen and stored at $-70^{\circ}$ C for shed Met analysis.

For the blocking studies with unlabeled onartuzumab, MKN45 tumor $(50-200 \mathrm{mg})$-bearing mice were divided into 2 groups, with one group receiving ${ }^{89} \mathrm{Zr}$-df-onartuzumab $(\sim 0.37$ $\mathrm{MBq}, \sim 3 \mu \mathrm{g}$ ) and the other group receiving a coinjection of ${ }^{89} \mathrm{Zr}$-df-onartuzumab plus $1 \mathrm{mg}$ of unlabeled onartuzumab. The mice were euthanized after $3 \mathrm{~d}$, and the processing of the blood and tissues was performed as described above. Statistical analysis of the differences between the 2 groups was done using the Student $t$ test.

\section{Small-Animal PET Studies}

Tumor-bearing mice were anesthetized using isoflurane $/ \mathrm{O}_{2}$ $(1.5 \%-3 \% \mathrm{v} / \mathrm{v})$ and imaged at various times after the intravenous injection of ${ }^{76} \mathrm{Br}$-onartuzumab $(1.85-5.55 \mathrm{MBq}, 30-50 \mu \mathrm{g})$ or ${ }^{89} \mathrm{Zr}$-df-onartuzumab (3.7-7.4 MBq, 64-128 $\mu \mathrm{g}$ ). Whole-body static images requiring $4-5$ bed positions were obtained (field of view, $2.0 \mathrm{~cm}$; total imaging time, 20-25 min) using the Advanced Technology Laboratory Animal Scanner (21). The images were reconstructed using a 2-dimensional ordered-subset expectation maximum from which regions of interest were drawn manually to determine the tissue uptake $\left(\mathrm{kBq} / \mathrm{cm}^{3}\right)$. The $\% \mathrm{ID} / \mathrm{g}$ normalized to a 20-g mouse was then determined using the formula $(100 \times$ [tissue uptake]/[injected dose] $) \times([$ body weight]/[20]).

\section{Determination of Plasma Shed Met Ectodomain and Total Tumor Met}

Met and plasma Met ectodomain (shed Met) levels were measured using a 2-site electrochemiluminescent immunoassay in which antibodies tagged with a ruthenium chelate (Sulfo-Tag; Meso Scale Discovery) were detected with a SECTOR Imager 2400 plate reader (Meso Scale Discovery) as described previously (11). A purified recombinant Met ectodomain-IgG-Fc fusion protein was used as a reference standard for quantitation of Met mass per mass total extracted cell protein. Tumor tissue extracts were prepared by physically disrupting tissue samples before clearing by centrifugation and analysis of Met content as described above. Correlations of shed Met, total tumor Met, and tumor radioactive onartuzumab content to tumor mass or total tumor mass were performed using the Spearman rank correlation coefficient (Prism)

\section{RESULTS}

\section{In Vitro Cell-Binding Studies}

Binding studies were performed with ${ }^{76} \mathrm{Br}$-onartuzumab and ${ }^{89} \mathrm{Zr}$-df-onartuzumab to determine the $\mathrm{K}_{\mathrm{d}}$, concentration of Met $\left(\mathrm{B}_{\max }\right.$, receptors per cell), and the percentage immunoreactive fraction using MKN-45 cells (12). Both ${ }^{76} \mathrm{Br}$-onartuzumab and ${ }^{89} \mathrm{Zr}$-df-onartuzumab had high specific binding for Met, ranging from $80 \%$ to $96 \%$ and from $80 \%$ to $98 \%$, respectively. The $\mathrm{K}_{\mathrm{d}}$ for ${ }^{76} \mathrm{Br}$-onartuzumab binding was $5.14 \pm 0.81 \mathrm{nM}(n=3)$, which was comparable to the $\mathrm{K}_{\mathrm{d}}$ for ${ }^{89} \mathrm{Zr}$-df-onartuzumab binding (6.12 \pm $1.18 \mathrm{nM} ; n=3)$. The estimated numbers of receptors per cell (calculated from $\left.\mathrm{B}_{\max }\right)$ were $1.07 \pm 0.28 \times 10^{6}(n=3)$ and $0.936 \pm 0.08 \times 10^{6}(n=3)$ for ${ }^{76} \mathrm{Br}$-onartuzumab and ${ }^{89} \mathrm{Zr}$-df-onartuzumab, respectively. The percentage immunoreactive fractions were also comparable, $85.4 \% \pm 6.9 \%$ $(n=3)$ and $81.9 \% \pm 0.7 \%(n=3)$ for ${ }^{76} \mathrm{Br}$-onartuzumab and ${ }^{89} \mathrm{Zr}$-df-onartuzumab, respectively. In similar saturation studies with SNU-16 and U87-MG, higher nonspecific binding was observed, ranging from $20 \%$ to $30 \%$ and from $55 \%$ to $85 \%$, respectively, which is consistent with moderate and lower levels of Met expression $(11,12)$. The $\mathrm{B}_{\max }$ was at least 6-fold higher for SNU-16 $\left(0.089 \pm 0.013 \times 10^{6}\right.$ $[n=3])$ than for U87-MG $\left(0.014 \pm 0.003 \times 10^{6}[n=3]\right)$. These data compare favorably with the expected levels of Met expression for these human cancer cell lines and further indicate that these tracers would be appropriate for imaging tumors with high to moderate Met expression $(>100,000$ receptors per cell); however, at lower Met expression levels $(<14,000$ receptors per cell), nonspecific interactions could impair the detection of specific Met binding.

\section{In Vivo ${ }^{76} \mathrm{Br}$-Onartuzumab, ${ }^{89} \mathrm{Zr}$-df-Onartuzumab, and ${ }^{89} \mathrm{Zr}$-Oxalate}

Biodistribution Studies. The biodistribution of ${ }^{76} \mathrm{Br}-$ onartuzumab was determined in MKN-45 xenografts from 6 to $72 \mathrm{~h}$ (Fig. 1A). The highest uptake was observed in tumor, blood, kidney, and lung, and uptake in tumor was similar to uptake in blood and these nontarget organs at all time points. In similar biodistribution studies using U87-MG xenografts, uptake in nontarget tissues was comparable to that in MKN-45 xenografts, but tumor uptake was approximately 2 -fold lower, consistent with the lower Met content of this line. Examining the ratio of $\% \mathrm{ID} / \mathrm{g}$ in the tumor and muscle (a nontarget tissue) to further assess the feasibility of ${ }^{76} \mathrm{Br}-$ onartuzumab as an imaging agent revealed that the highest tumor-to-muscle (TM) ratios, $5: 1$ to $6: 1$, occurred after $24 \mathrm{~h}$ for MKN-45 xenografts (Table 1). For the U87 xenografts, the TM ratio ranged from $3: 1$ to $4: 1$ at 24 and $48 \mathrm{~h}$, respectively, or approximately 1.5- to 2-fold lower, consistent with lower Met expression. 

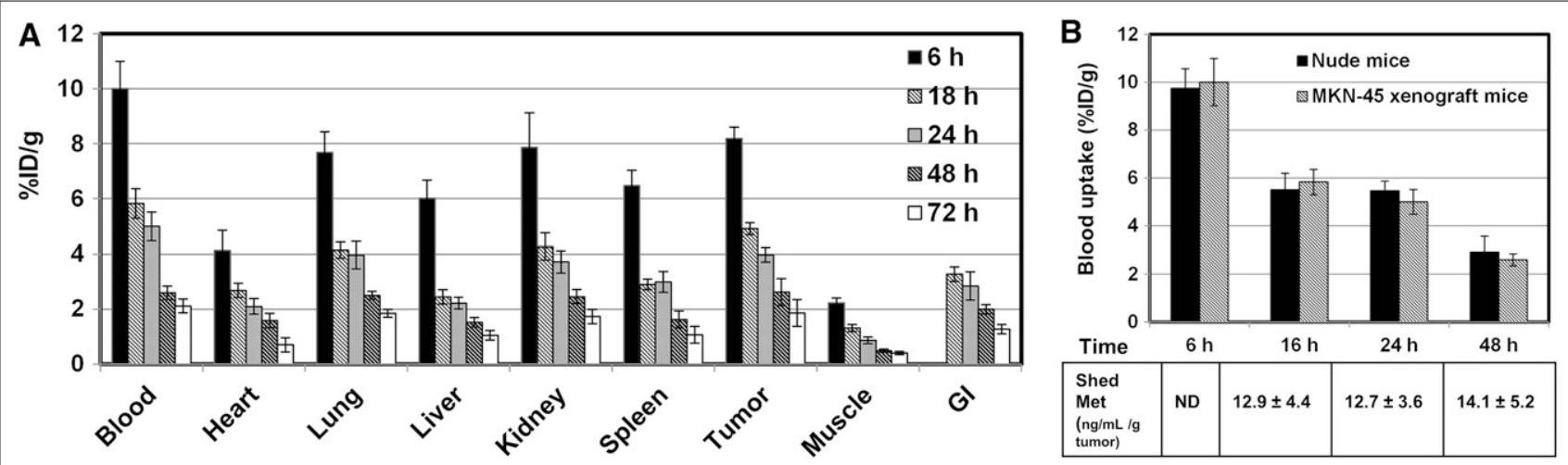

FIGURE 1. (A) Biodistribution of ${ }^{76} \mathrm{Br}$-onartuzumab in MKN-45 xenografts from 6 to $72 \mathrm{~h}$. Each time point represents mean \%ID/g $\pm \mathrm{SD}$ of ${ }^{76} \mathrm{Br}$-onartuzumab ( $n=3$ for 72 -h group; $n=4$ for all other time points). (B) Comparison of ${ }^{76} \mathrm{Br}$-onartuzumab blood uptake (\%ID/g) in nude and MKN-45 xenograft mice. Each time point represents mean \%ID/g \pm SD of ${ }^{76} \mathrm{Br}$-onartuzumab (nude mice, $n=5 ; \mathrm{MKN}-45 \mathrm{xenografts}, n=4$ ). The table shows corresponding plasma shed Met ectodomain concentrations ( $\mathrm{ng} / \mathrm{mL} / \mathrm{g}$ tumor) determined from same MKN-45 xenograft mouse blood samples; each value represents mean concentration $\pm \mathrm{SD}(n=4)$. Gl $=$ gastrointestinal tract; ND $=$ not determined.

Because uptake of ${ }^{76} \mathrm{Br}$-onartuzumab in blood and tumors was similar over time, studies were undertaken to determine whether the levels of shed Met ectodomain in the blood of tumor-bearing mice differed from that of control mice, potentially influencing the blood clearance. Both of these Metexpressing tumors have been shown to shed Met ectodomain into the systemic circulation $(11,12)$. For these studies, the biodistribution of ${ }^{76} \mathrm{Br}$-onartuzumab was determined in nontumor-bearing nude mice after $6,16,24$, and $48 \mathrm{~h}$ and compared with the uptake $(\% \mathrm{ID} / \mathrm{g})$ shown in Figure $1 \mathrm{~A}$ for MKN-45 xenografts. At all time points, the \%ID/g in blood (Fig. 1B), heart, kidneys, lungs, or spleen was not significantly different $(P<0.05)$; significant differences were observed in liver uptake at $6 \mathrm{~h}(28 \%$ decrease $)$ and in muscle at $6 \mathrm{~h}$ (24\% decrease), $16 \mathrm{~h}$ (47\% decrease), and $48 \mathrm{~h}$ (53\% increase) in the nude mice versus the xenograft mice. The differences in muscle uptake may be attributable to poor counting statistics because this tissue has relatively low radioactivity. The significant difference in the liver uptake most likely reflects age and body weight differences between the 2 groups. Although the uptake was normalized to a $20 \mathrm{-g}$ mouse, this normalization did not take into account agerelated changes in metabolism. In this case, the xenograft mice at $6 \mathrm{~h}$ were older $(\sim 12 \mathrm{wk})$ and weighed more (almost $30 \mathrm{~g}$ ) than the nude mice (age, $\sim 5 \mathrm{wk}$; weight, 19-24 g); hence, the younger nude mice would be expected to have faster liver metabolism and clearance than the older xenograft mice, resulting in the observed decreased liver uptake. Further, the concentration of shed Met ectodomain (Fig.1B; $\mathrm{ng} / \mathrm{mL}$ per gram of tumor mass) in plasma samples obtained from these MKN-45 xenografts remained relatively unchanged at 16,24 , and $48 \mathrm{~h}$, whereas the ${ }^{76} \mathrm{Br}$-onartuzumab blood uptake steadily decreased. The ${ }^{76} \mathrm{Br}$-onartuzumab blood concentration (at the time of injection) was approximately $12 \mathrm{nM}$, which was approximately a 100-fold excess, compared with shed Met blood concentrations of approximately $0.126 \mathrm{nM}$ for a 1 -g tumor (representative of the largest tumor and highest shed Met blood concentration). Overall, these results indicate that the presence of shed Met in tumor-bearing mice does not alter the pharmacokinetics and clearance of ${ }^{76} \mathrm{Br}$-onartuzumab.

The biodistribution of ${ }^{89} \mathrm{Zr}$-df-onartuzumab was determined in MKN-45 xenografts from $18 \mathrm{~h}$ to $5 \mathrm{~d}$ (Fig. 2). ${ }^{89} \mathrm{Zr}$-dfonartuzumab uptake $(\% \mathrm{ID} / \mathrm{g})$ in the nontarget tissues-blood, heart, lungs, gastrointestinal tract, and muscle-decreased slowly, with less than a 50\% reduction in $\% \mathrm{ID} / \mathrm{g}$ from $18 \mathrm{~h}$ to $5 \mathrm{~d}$. In contrast, uptake in the liver and kidneys increased over the time course, suggesting hepatobiliary and renal clearance. At $18 \mathrm{~h},{ }^{89} \mathrm{Zr}$-df-onartuzumab uptake in tumor was comparable to that in blood, kidneys, and lung, but from 2 to $5 \mathrm{~d}$, uptake in tumor was at least 2 -fold greater than that

TABLE 1

Comparison of TM Ratios of ${ }^{89} \mathrm{Zr}$-df-Onartuzumab and ${ }^{76} \mathrm{Br}$-Onartuzumab in $\mathrm{MKN}-45$ Xenografts

\begin{tabular}{|c|c|c|c|c|c|c|c|}
\hline \multirow[b]{2}{*}{ TM ratios for... } & \multicolumn{7}{|c|}{ Uptake time (h) } \\
\hline & 6 & 18 & 24 & 48 & 72 & 96 & 120 \\
\hline${ }^{89} \mathrm{Zr}$-df-onartuzumab & - & $6.4(0.4)$ & $7.1(1.0)$ & $13.2(2.4)$ & $12.2(2.3)$ & $19.6(2.4)$ & $26.6(0.9)$ \\
\hline${ }^{76} \mathrm{Br}$-onartuzumab & $3.7(0.4)$ & $3.8(0.4)$ & $4.5(0.9)$ & $5.8(0.7)$ & $5.3(0.6)$ & - & - \\
\hline
\end{tabular}




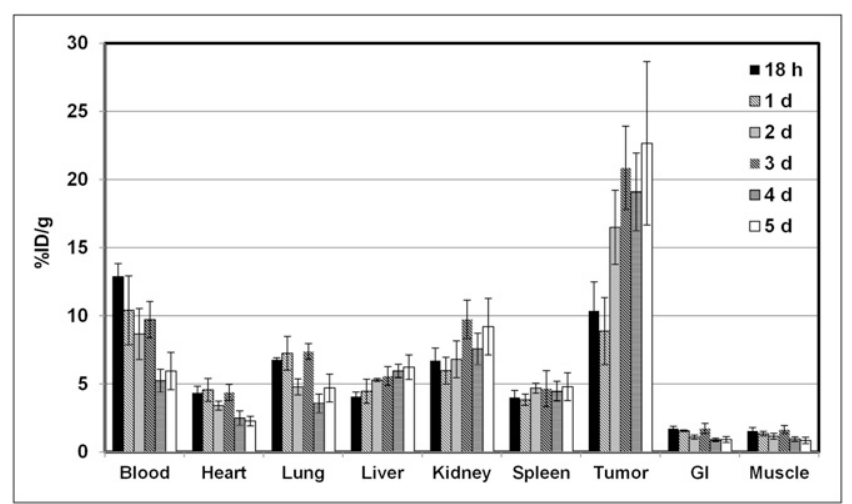

FIGURE 2. Biodistribution of $89 \mathrm{Zr}$-df-onartuzumab in $\mathrm{MKN}-45$ xenografts from $18 \mathrm{~h}$ to $5 \mathrm{~d}$. Each bar represents $\% I D / g \pm S D$ of ${ }^{89} \mathrm{Zr}$-df-onartuzumab ( $n=5,18$-h group; $n=4$, other time points). $\mathrm{Gl}=$ gastrointestinal tract.

in blood, kidneys, and lung. At 2, 3, 4, and $5 \mathrm{~d}$, the tumors had the highest uptake, ranging from 16.5 to $22.5 \% \mathrm{ID} / \mathrm{g}$. In a similar biodistribution study using U87-MG xenografts, the uptake in nontarget tissues was comparable to the results of the MKN-45 xenograft study shown in Figure 2. However, uptake in the U87 tumors was 1.8- and 3.0-fold lower than that in the MKN-45 tumors at 3 and $5 \mathrm{~d}$, respectively. The highest TM ratios of 13.2, 26.5, and 26.6 occurred at 2, 3, and $5 \mathrm{~d}$, respectively, for the MKN-45 xenografts, whereas TM ratios for the U87 xenografts ranged from 7:1 to 9:1 over the 5-d time course (Fig. 3). The 2- to 3-fold reduction in uptake by U87 tumors is consistent with the lower Met expression of this cell line.

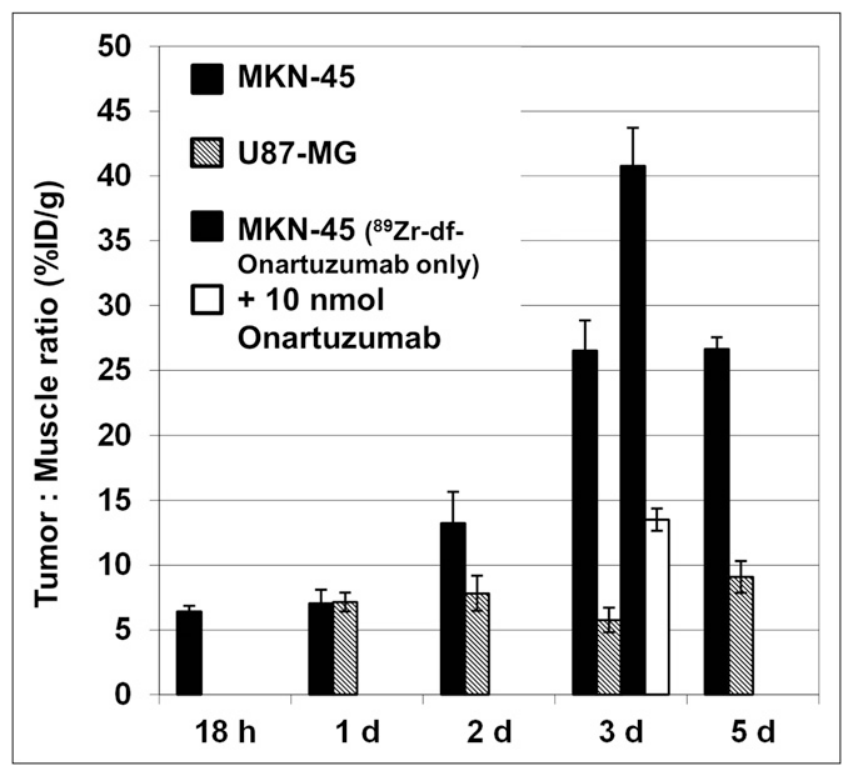

FIGURE 3. Comparison of TM ratios (\%ID/g) of ${ }^{89} \mathrm{Zr}$-df-onartuzumab in $\mathrm{MKN}-45$ and U87-MG xenografts from $18 \mathrm{~h}$ to $5 \mathrm{~d}$. Bars represent mean TM $\pm \mathrm{SD}(n=4)$. Bars at $3 \mathrm{~d}$ include TM from ${ }^{89} \mathrm{Zr}$-dfonartuzumab competitive blocking study in MKN-45 xenografts injected with ${ }^{89} \mathrm{Zr}$-df-onartuzumab only or ${ }^{89} \mathrm{Zr}$-df-onartuzumab plus $10 \mathrm{nmol}$ onartuzumab.
Blocking studies were performed with MKN-45 xenografts in which ${ }^{89} \mathrm{Zr}$-df-onartuzumab (0.0133 nmol onartuzumab) or ${ }^{89} \mathrm{Zr}$-df-onartuzumab plus $10 \mathrm{nmol}$ of unlabeled onartuzumab was injected. Uptake (\%ID/g) determined after $3 \mathrm{~d}$ was comparable for both groups in the blood, heart, lungs, spleen, liver, gastrointestinal tract, and muscle. Kidney uptake increased approximately 2.5 -fold, and tumor uptake decreased approximately 3.8 -fold, suggesting competitive blocking by unlabeled onartuzumab in the tumor. The TM ratios for the blocked group, compared with mice injected with ${ }^{89} \mathrm{Zr}$-df-onartuzumab alone, were significantly reduced $(67 \%, P<0.05)$, indicating specific Met binding in vivo (Fig. 3).

To determine the biologic fate of free ${ }^{89} \mathrm{Zr}$ that may result from ${ }^{89} \mathrm{Zr}$-df-onartuzumab metabolism, the biodistribution of ${ }^{89} \mathrm{Zr}$-oxalate (which has a biodistribution characteristic of zirconium (22)) was determined in MKN-45 xenograft mice from 1 to $5 \mathrm{~d}$ (Fig. 4). The highest retention and accumulation of radioactivity, ranging from 20 to $30 \% \mathrm{ID} / \mathrm{g}$, occurred in bone over the entire course and was 3- to 8-fold higher than ${ }^{89} \mathrm{Zr}$-df-onartuzumab bone uptake. The greatest clearance of radioactivity from 1 to $5 \mathrm{~d}$ was observed in blood $(>90 \%)$, whereas clearance from other tissues was slower (55\%-10\% decreases). The tumors retained at least $80 \%$ of the radioactivity from 1 to $5 \mathrm{~d}$, with uptake ranging from 2.1 to $2.6 \% \mathrm{ID} / \mathrm{g}$, which was higher than in any other tissues except bone. ${ }^{89} \mathrm{Zr}$ tumor uptake $(2 \% \mathrm{ID} / \mathrm{g})$ represented less than $10 \%$ of the ${ }^{89} \mathrm{Zr}$-df-onartuzumab tumor uptake (22 and $25 \% \mathrm{ID} / \mathrm{g}$ ) at 3 and $5 \mathrm{~d}$, respectively.

The uptake $(\% \mathrm{ID} / \mathrm{g})$ of ${ }^{89} \mathrm{Zr}$-df-onartuzumab and ${ }^{76} \mathrm{Br}-$ onartuzumab, in blood, muscle, and MKN-45 tumors from 6 to $120 \mathrm{~h}$, is compared in Figure 5. ${ }^{89} \mathrm{Zr}$-df-onartuzumab tumor uptake remained steady or increased over the 5-d time course, whereas ${ }^{76} \mathrm{Br}$-onartuzumab tumor uptake steadily decreased over the 3-d time course (Fig. 5). Although mus-

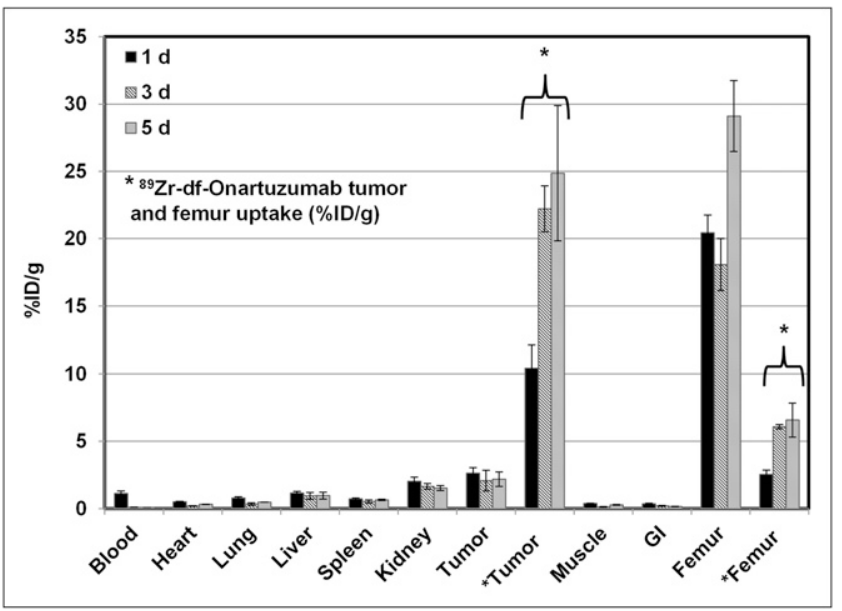

FIGURE 4. Biodistribution of ${ }^{89} \mathrm{Zr}$-oxalate in $\mathrm{MKN}-45$ xenografts after 1, 3, and $5 \mathrm{~d}$; ${ }^{89} \mathrm{Zr}$-df-onartuzumab tumor and femur uptake is used for comparison. Each bar represents $\% I D / g \pm S D\left({ }^{89} \mathrm{Zr}\right.$-oxalate, $n=3$; ${ }^{89} \mathrm{Zr}$-df-onartuzumab, $n=3$ ). $\mathrm{Gl}=$ gastrointestinal tract. 


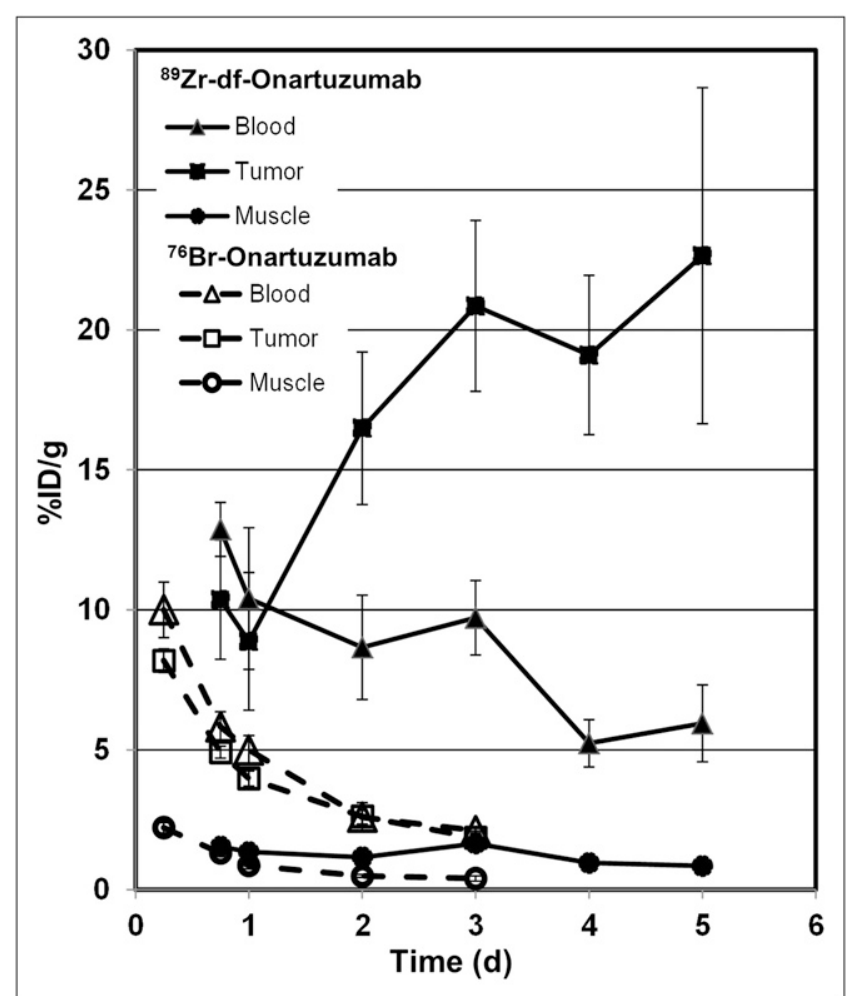

FIGURE 5. Comparison of blood, tumor, and muscle uptake of $89 \mathrm{Zr}-$ df-onartuzumab and ${ }^{76} \mathrm{Br}$-onartuzumab in MKN-45 xenografts from $6 \mathrm{~h}$

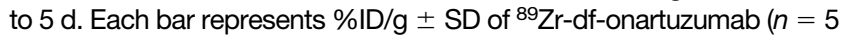
[18 h]; $n=4$ [other times]) or ${ }^{76} \mathrm{Br}$-onartuzumab $(n=4)$.

cle uptake over time was similar for both tracers, the radioactivity remaining in the blood differed for each agent. After $2 \mathrm{~d},{ }^{89} \mathrm{Zr}$-df-onartuzumab tumor uptake exceeded the blood levels, whereas ${ }^{76} \mathrm{Br}$-onartuzumab tumor uptake mirrored blood levels over the entire time course. Thus, ${ }^{76} \mathrm{Br}$-onartuzumab showed lower retention in the tumors relative to ${ }^{89} \mathrm{Zr}$-df-onartuzumab, with clearance similar to the radioactivity in blood.

${ }^{89} \mathrm{Zr}$-df-onartuzumab had the highest TM ratios-19.6 and 26.6-at 96 and $120 \mathrm{~h}$, respectively (Table 1). Over the entire time course, TM ratios for ${ }^{76} \mathrm{Br}$-onartuzumab were approximately 2 -fold lower than those for ${ }^{89} \mathrm{Zr}$-dfonartuzumab (Table 1). The ${ }^{76} \mathrm{Br}$-onartuzumab $\mathrm{TM}$ ratios remained relatively unchanged from 24 to $72 \mathrm{~h}$, whereas the ${ }^{89} \mathrm{Zr}$-df-onartuzumab $\mathrm{TM}$ ratios increased from 24 to $120 \mathrm{~h}$ (Table 1). Similarly, ${ }^{76} \mathrm{Br}$-onartuzumab tumor-toblood ratios were always less than 1 at $6,16,24,48$, and $72 \mathrm{~h}$, whereas ${ }^{89} \mathrm{Zr}$-df-onartuzumab TM ratios were approximately 2 at $72 \mathrm{~h}$ and increased to approximately 4 at $120 \mathrm{~h}$.

Small-Animal PET Studies. Small-animal PET studies with ${ }^{76} \mathrm{Br}$-onartuzumab were performed in MKN-45 or U87MG xenografts, with imaging from $18 \mathrm{~h}$ to $3 \mathrm{~d}$. MKN-45 tumors were visualized as early as $18 \mathrm{~h}$, with image quality improving at $24 \mathrm{~h}$ and attaining a TM ratio of approximately 5 (Fig. 6A). Despite an increase the ${ }^{76} \mathrm{Br}$-onartuzumab dose from 11.1 to $18.5 \mathrm{MBq}$, images obtained at 48 and $72 \mathrm{~h}$ showed no improvement, because of relatively low levels of radioactivity and lack of ${ }^{76} \mathrm{Br}$-onartuzumab retention in tumors. Therefore, $24 \mathrm{~h}$ proved to be the optimum imaging time. At $24 \mathrm{~h}, \mathrm{U} 87-\mathrm{MG}$ tumors were more difficult to discern than MKN-45 tumors, consistent with their lower Met expression level.

Imaging studies of MKN-45 xenografts with ${ }^{89} \mathrm{Zr}$-dfonartuzumab indicated that although tumors could be visualized at $18 \mathrm{~h}$, image quality improved over the 5-d period (Fig. 6B). At 5 d, the MKN-45 TM ratio was 26:1; the increase in TM ratios over the 5-d period reflects better tumor retention and clearance from nontarget tissues.

\section{Correlation of ${ }^{76} \mathrm{Br}$-Onartuzumab and ${ }^{89} \mathrm{Zr}$-df-Onartuzumab Uptake with Shed Met and Tumor Met}

Plasma and tumor samples from naïve MKN-45 xenografts or MKN-45 xenografts injected with ${ }^{76} \mathrm{Br}$-onartuzumab or ${ }^{89} \mathrm{Zr}$-df-onartuzumab were analyzed for shed Met ectodomain and total tumor Met content, and then the potential associations between these values to tumor mass or the total tumor radioactive content (percentage injected dose per tumor) were determined (Fig. 7). In naïve xenografts, significant direct correlations were found between tumor mass and shed Met (Fig. 7A), tumor mass and total tumor Met content (Fig. 7B), and total tumor Met content and shed Met (Fig. 7C). The total Met contents of tumor samples excised from xenografts injected with ${ }^{89} \mathrm{Zr}$-df-onartuzumab were also significantly correlated with the tumor mass (Fig. 7E) and with the ${ }^{89} \mathrm{Zr}$-df-onartuzumab total tumor uptake (\%ID) (Fig. 7F). Similar results were obtained using tumor samples from xenografts injected with ${ }^{76} \mathrm{Br}$-onartuzumab (data not shown). The similarity in correlations from naïve tumors and tumors labeled with ${ }^{76} \mathrm{Br}$-onartuzumab or ${ }^{89} \mathrm{Zr}$-df-onartuzumab indicates that the tracer did not interfere with the Met content determinations. The lower slope observed in the correlation of ${ }^{76} \mathrm{Br}$-onartuzumab tumor uptake to tumor mass, compared with that of ${ }^{89} \mathrm{Zr}$-df-onartuzumab (Fig. 7D), most likely reflects the overall decreased tumor retention of ${ }^{76} \mathrm{Br}$-onartuzumab. The significant correlations between ${ }^{89} \mathrm{Zr}$-df-onartuzumab or ${ }^{76} \mathrm{Br}$-onartuzumab tumor uptake and total tumor Met content (Fig. 7F) indicate that radiolabeled onartuzumab tumor uptake directly reflects tumor Met concentrations. Plasma shed Met values from xenografts injected with ${ }^{76} \mathrm{Br}$-onartuzumab or ${ }^{89} \mathrm{Zr}$-df-onartuzumab also correlated significantly with tumor mass (data not shown; $P<0.0001$ and $<0.03$, respectively), comparable to results with the naive xenografts, indicating that neither ${ }^{76} \mathrm{Br}$-onartuzumab nor ${ }^{89} \mathrm{Zr}$-df-onartuzumab affected Met shedding.

\section{DISCUSSION}

Onartuzumab labeled with ${ }^{76} \mathrm{Br}$ or ${ }^{89} \mathrm{Zr}$ retained most of its biologic activity ( $>80 \%$ immunoreactivity) and displayed nanomolar binding affinity for Met. Both agents could quantitatively distinguish a high-Met-expressing cell line (MKN-45) from a low-Met-expressing cell line (U87- 
A

FIGURE 6. Representative coronal PET images from mouse with MKN-45 tumor on right thigh injected with ${ }^{76} \mathrm{Br}$-onartuzumab (tumor volume, $\left.\sim 0.7 \mathrm{~cm}^{3}\right)(\mathrm{A})$ and ${ }^{89} \mathrm{Zr}$-dfonartuzumab (tumor volume, $\sim 0.4 \mathrm{~cm}^{3}$ ) (B).

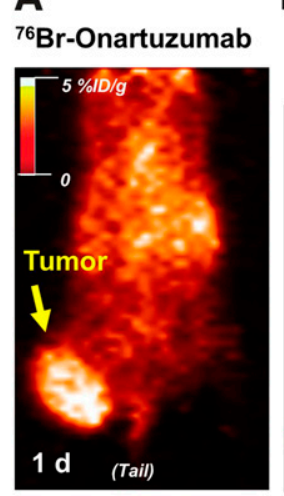

B

${ }^{89} \mathrm{Zr}$-df-Onartuzumab
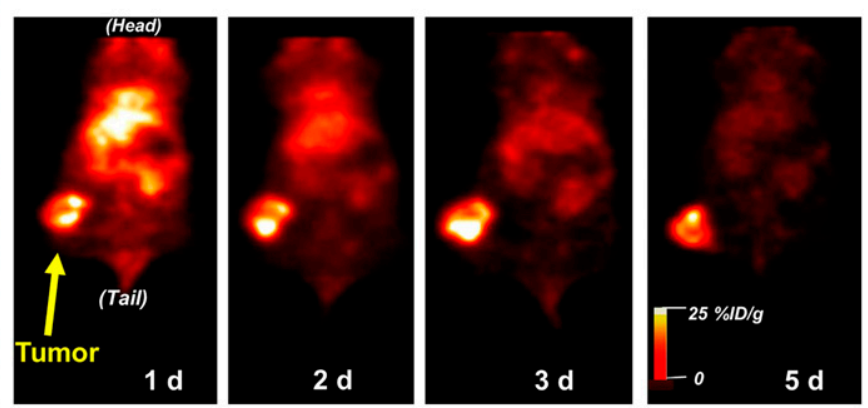

MG) in vitro. Although these in vitro parameters were similar, in vivo biodistribution and imaging studies revealed that ${ }^{89} \mathrm{Zr}$-df-onartuzumab attained higher tumor-to-nontarget tissue ratios over time, providing higher-quality images than ${ }^{76} \mathrm{Br}$-onartuzumab in MKN-45 xenografts.

Compared with ${ }^{89} \mathrm{Zr}$-df-onartuzumab, ${ }^{76} \mathrm{Br}$-onartuzumab did not accumulate in MKN-45 tumors at later time points but decreased at a rate similar to that in nontarget tissues, resulting in no improvement of TM ratios over time. The lack of further accumulation may in part be related to the direct labeling method used for ${ }^{76} \mathrm{Br}$-onartuzumab; available tyrosine residues are labeled in the presence of a strong oxidizing agent, and excessive protein oxidation can result in lower immunoreactivity. In addition, directly labeled antibodies internalized into cells are characteristically subject to debromination, thereby losing their label (23). In this case, onartuzumab behaves as an antagonist, unable to cause dimerization; thus, internalization would be expected to be minimal and not necessarily mediated by activation of Met (10). Because ${ }^{76} \mathrm{Br}$-onartuzumab immunoreactivity was preserved in our studies, in vivo debromination and metabolism are most likely responsible for the lower tumor uptake relative to ${ }^{89} \mathrm{Zr}$-df-onartuzumab. Alternative radiosynthetic methods have been described for labeling antibodies with ${ }^{76} \mathrm{Br}$, including indirect methods and an enzymatic method (bromoperoxidase), which claim to improve in vivo stability and thereby increase tumor accumulation and retention (7).

In contrast, indirectly labeled antibodies coupled with a metal chelate, such as ${ }^{89} \mathrm{Zr}$-df-onartuzumab, tend to have increased accumulations in target cells because of trapping of radioactive metabolites from internalization (23). Our results are similar to those of other studies in which tumor uptake was increased with monoclonal antibodies labeled with ${ }^{89} \mathrm{Zr}$, a residualizing radionuclide, compared with ${ }^{124} \mathrm{I}$, a nonresidu-
FIGURE 7. Correlation of plasma shed Met, total Met tumor content, and radioactive tumor uptake (\%ID per tumor) with tumor mass and Met abundance (all correlations determined using Spearman nonparametric analysis). (A-C) Correlations of plasma and tumor samples from naïve MKN-45 xenografts: $r=0.8167, P<$ 0.02 (A); $r=0.9321, P<0.0001$ (B); and $r=$ 0.8167, $P<0.01$ (C). (D-F) Tumor samples from MKN-45 xenografts previously injected with radiolabeled onartuzumab. (D) Correlations of radiolabeled onartuzumab tumor uptake to tumor mass: ${ }^{76} \mathrm{Br}$-onartuzumab $(\bigcirc)$, \%ID per tumor determined after $24 \mathrm{~h}(r=0.9879 ; P<$ 0.0001); ${ }^{89} \mathrm{Zr}$-df-onartuzumab ( $\left.\bullet\right), \% \mathrm{ID}$ per tumor determined after 3,4 , and $5 \mathrm{~d}(r=0.9357$; $P<0.0001$ ). (E) Correlation of total tumor Met to mass: tumor samples were taken after 0.75 , $1,2,3,4$, and $5 \mathrm{~d}$ of $89 \mathrm{Zr}$-df-onartuzumab uptake and assayed for total Met content $(r=$ 0.9721; $P<0.0001$ ). (F) Correlation of ${ }^{89} \mathrm{Zr}$-dfonartuzumab tumor uptake (\%ID per tumor after 3, 4, and $5 \mathrm{~d}$ of uptake) to total tumor Met determinations $(r=0.9385 ; P<0.0001)$.

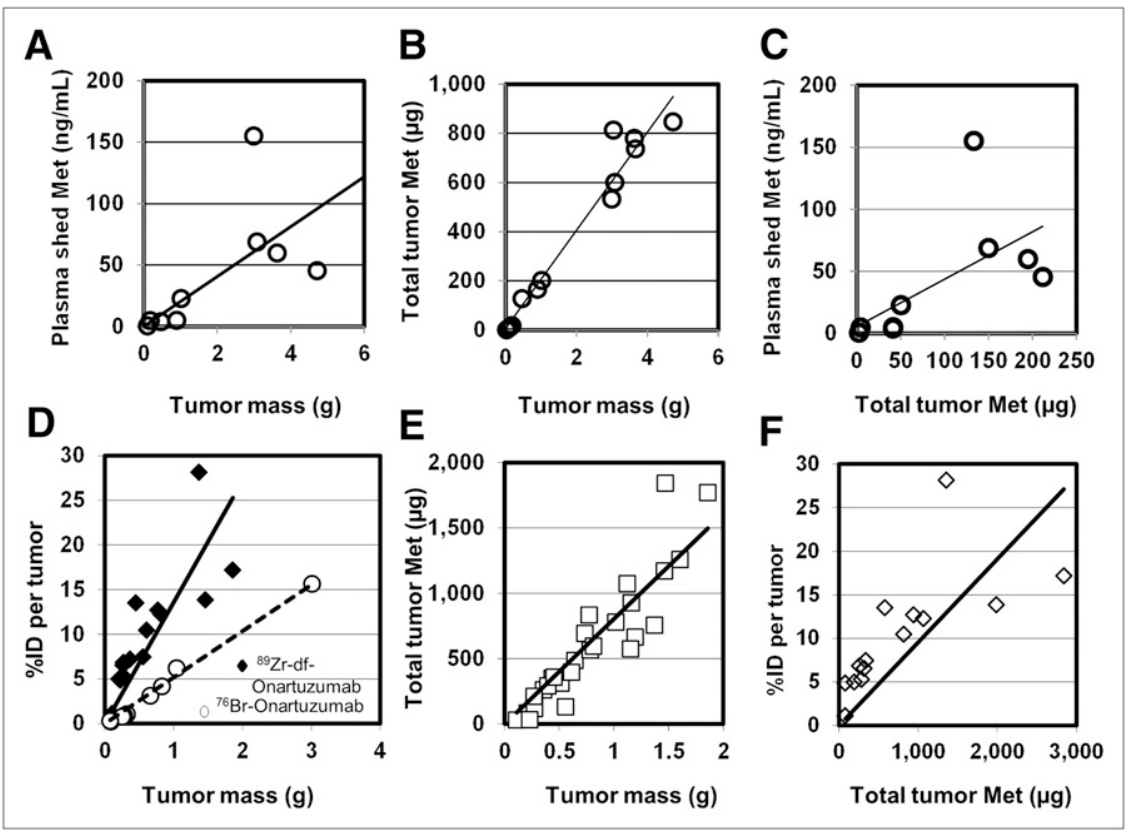


alizing radionuclide (9). In MKN-45 tumors, we observed substantially greater retention of ${ }^{89} \mathrm{Zr}$-df-onartuzumab (22 and $25 \% \mathrm{ID} / \mathrm{g}$ at 3 and $5 \mathrm{~d}$, respectively) than of ${ }^{89} \mathrm{Zr}$-oxalate ( 2.1 and $2.2 \% \mathrm{ID} / \mathrm{g}$ at 3 and $5 \mathrm{~d}$, respectively), indicating that most of the tumor uptake would be expected to represent binding to Met rather than free ${ }^{89} \mathrm{Zr}$.

Although ${ }^{89} \mathrm{Zr}$-df-onartuzumab uses an indirect labeling method conferring increased tumor retention, we observed a high bone uptake ranging between 6 and $7 \% \mathrm{ID} / \mathrm{g}$ at 3 and $5 \mathrm{~d}$, respectively, that could theoretically affect clinical application. In agreement with our results, ${ }^{89} \mathrm{Zr}$-oxalate and other solvated or chelated forms of ${ }^{89} \mathrm{Zr}$ had high bone accumulation in mice, and this accumulation was primarily associated with the bones and epiphyses rather than bone marrow (22). Further, Abou et al. (22) showed that the bone uptake was dependent on the strength of the chelate. Although these preclinical mouse studies predicted potentially high bone uptake of free ${ }^{89} \mathrm{Zr}$ in human studies, successful ${ }^{89} \mathrm{Zr}$ immuno-PET clinical studies have been performed in which bone uptake and radiation doses to bone marrow were minimal (24), suggesting that with the appropriate radiochemistry and a strong chelate, high ${ }^{89} \mathrm{Zr}$ bone uptake can be avoided.

In addition to the longer radioactive half-life, which better accommodates the longer biologic half-life of onartuzumab and increased tumor retention, ${ }^{89} \mathrm{Zr}$-df-onartuzumab in vivo tumor uptake was Met-specific and sensitive to changes in Met densities. Unlabeled onartuzumab significantly blocked tumor uptake, indicating that ${ }^{89} \mathrm{Zr}$-df-onartuzumab and onartuzumab are competing for the same binding site. The substantially decreased ${ }^{89} \mathrm{Zr}$-df-onartuzumab uptake observed in U87-MG tumors relative to MKN-45 tumors represents reduced Met densities in U87-MG tumors, which are known to have low Met expression. Further, the significant correlations among ${ }^{89} \mathrm{Zr}$-df-onartuzumab tumor uptake, tumor mass, and total tumor Met content confirm that ${ }^{89} \mathrm{Zr}$-dfonartuzumab tumor uptake is directly related to tumor Met density. However, in larger tumors ${ }^{89} \mathrm{Zr}$-df-onartuzumab uptake may be decreased because of necrosis rather than real changes in Met densities of the viable tumor tissue. In this case, for the ${ }^{89} \mathrm{Zr}$-df-onartuzumab uptake to accurately correspond to the tumor Met density, viable uptake excluding the necrotic regions would need to be determined from the PET images. The presence of shed Met did not appear to alter the ${ }^{76} \mathrm{Br}$-onartuzumab biodistributions in nude mice versus MKN-45 xenografts, which is most likely a consequence of the high molar ratio of ${ }^{89} \mathrm{Zr}$-df-onartuzumab to shed Met $(>100$-fold). Although shed Met concentrations were comparable from naïve and radiolabeled onartuzumab, suggesting that radiolabeled onartuzumab does not interact with shed Met, this does not preclude the possibility that radiolabeled onartuzumab binds to a distinct site that does not cross-react with the immunoassay detection antibody. More importantly, these results indicate that shed Met would not be expected to interfere with the delivery of radiolabeled onartuzumab to its target.

\section{CONCLUSION}

The results of our study indicate that ${ }^{89} \mathrm{Zr}$-df-onartuzumab may prove to be an effective immuno-PET agent in humans. However, onartuzumab does not recognize murine Met, and thus our preclinical studies do not address onartuzumab uptake that might occur in human tissues that normally express Met. Initial imaging studies in humans with ${ }^{89} \mathrm{Zr}$-df-onartuzumab designed to determine uptake in nontarget tissues will be important for determining imaging feasibility. Because ${ }^{89} \mathrm{Zr}$-df-onartuzumab represents the radiolabeled version of the therapeutic onartuzumab, this agent may aid in drug development by identifying tissues that may be subject to onartuzumab-associated toxicities, assessing responses to onartuzumab treatment, establishing appropriate dosing for optimal tumor targeting, and tracking in vivo the disposition of onartuzumab in individual patients. ${ }^{89} \mathrm{Zr}$-df-onartuzumab imaging may also prove useful in the development of smallmolecule Met tyrosine kinase inhibitors and other Met-targeted agents for monitoring therapeutic responses in which decreased uptake would be expected in Met-positive tumors. More generally, ${ }^{89} \mathrm{Zr}$-df-onartuzumab has potential utility for imaging Met to identify patients for treatment with Met-targeted therapeutics and to identify the emergence of Met-driven acquired resistance to other molecularly targeted cancer therapies.

\section{DISCLOSURE STATEMENT}

The costs of publication of this article were defrayed in part by the payment of page charges. Therefore, and solely to indicate this fact, this article is hereby marked "advertisement" in accordance with 18 USC section 1734.

\section{ACKNOWLEDGMENT}

No potential conflict of interest relevant to this article was reported.

\section{REFERENCES}

1. Birchmeier C, Birchmeier W, Gherardi E, Vande Woude GF. Met, metastasis, motility and more. Nat Rev Mol Cell Biol. 2003;4:915-925.

2. Peruzzi B, Bottaro DP. Targeting the c-Met signaling pathway in cancer. Clin Cancer Res. 2006;12:3657-3660.

3. Cappuzzo F, Janne PA, Skokan M, et al. MET increased gene copy number and primary resistance to gefitinib therapy in non-small-cell lung cancer patients. Ann Oncol. 2009;20:298-304.

4. Martens T, Schmidt NO, Eckerich C, et al. A novel one-armed anti-c-Met antibody inhibits glioblastoma growth in vivo. Clin Cancer Res. 2006;12:6144-6152.

5. Jin H, Yang R, Zheng Z, et al. MetMAb, the one-armed 5D5 anti-c-Met antibody, inhibits orthotopic pancreatic tumor growth and improves survival. Cancer Res. 2008;68:4360-4368.

6. Surati M, Patel P, Peterson A, Salgia R. Role of MetMAb (OA-5D5) in c-MET active lung malignancies. Expert Opin Biol Ther. 2011;11:1655-1662.

7. Nayak TK, Brechbiel MW. Radioimmunoimaging with longer-lived positron-emitting radionuclides: potentials and challenges. Bioconjug Chem. 2009;20:825-841.

8. Verel I, Visser GW, Boellaard R, et al. Quantitative ${ }^{89} \mathrm{Zr}$ immuno-PET for in vivo scouting of ${ }^{90} \mathrm{Y}$-labeled monoclonal antibodies in xenograft-bearing nude mice. J Nucl Med. 2003;44:1663-1670.

9. Perk LR, Stigter-van Walsum M, Visser GW, et al. Quantitative PET imaging of Met-expressing human cancer xenografts with ${ }^{89} \mathrm{Zr}$-labelled monoclonal antibody DN30. Eur J Nucl Med Mol Imaging. 2008;35:1857-1867. 
10. Prat M, Crepaldi T, Pennacchietti S, Bussolino F, Comoglio PM. Agonistic monoclonal antibodies against the Met receptor dissect the biological responses to HGF. J Cell Sci. 1998;111:237-247.

11. Athauda G, Giubellino A, Coleman JA, et al. c-Met ectodomain shedding rate correlates with malignant potential. Clin Cancer Res. 2006;12:4154-4162.

12. Bachleitner-Hofmann T, Sun MY, Chen CT, et al. HER kinase activation confers resistance to MET tyrosine kinase inhibition in MET oncogene-addicted gastric cancer cells. Mol Cancer Ther. 2008;7:3499-3508.

13. Martin TA, Jiang WG. Hepatocyte growth factor and its receptor signalling complex as targets in cancer therapy. Anticancer Agents Med Chem. 2010;10:2-6.

14. Perk LR, Vosjan MJ, Visser GW, et al. p-Isothiocyanatobenzyl-desferrioxamine: a new bifunctional chelate for facile radiolabeling of monoclonal antibodies with zirconium-89 for immuno-PET imaging. Eur J Nucl Med Mol Imaging. 2010; 37:250-259.

15. Verel I, Visser GW, Boellaard R, Stigter-van Walsum M, Snow GB, van Dongen GA. ${ }^{89} \mathrm{Zr}$ immuno-PET: comprehensive procedures for the production of ${ }^{89} \mathrm{Zr}$-labeled monoclonal antibodies. J Nucl Med. 2003;44:1271-1281.

16. Szajek LP, Kao CHK, Kiesewetter DO, et al. Semi-remote production of Br-76 and preparation of high specific activity radiobrominated pharmaceuticals for PET studies. Radiochim Acta. 2004;92:291-295.
17. Lindmo T, Boven E, Cuttitta F, Fedorko J, Bunn PA Jr. Determination of the immunoreactive fraction of radiolabeled monoclonal antibodies by linear extrapolation to binding at infinite antigen excess. J Immunol Methods. 1984;72:77-89.

18. Choi CW, Lang L, Lee JT, et al. Biodistribution of ${ }^{18} \mathrm{~F}$ - and ${ }^{125} \mathrm{I}$-labeled anti-Tac disulfide-stabilized Fv fragments in nude mice with interleukin 2 alpha receptorpositive tumor xenografts. Cancer Res. 1995;55:5323-5329.

19. Morris BJ. Specific radioactivity of radioimmunoassay tracer determined by selfdisplacement: a re-evaluation. Clin Chim Acta. 1976;73:213-216.

20. Guide for the Care and Use of Laboratory Animals. Bethesda, MD: National Institutes of Health; 1985. NIH publication 85-23.

21. Seidel J, Vaquero JJ, Green MV. Resolution uniformity and sensitivity of the NIH atlas small animal scanner: comparison to simulated LSO scanners without depth-of-interaction capability. IEEE Trans Nucl Sci. 2003;50:1347-1350.

22. Abou DS, Ku T, Smith-Jones PM. In vivo biodistribution and accumulation of ${ }^{89} \mathrm{Zr}$ in mice. Nucl Med Biol. 2011;38:675-681.

23. Wu AM, Olafsen T. Antibodies for molecular imaging of cancer. Cancer J. 2008;14:191-197.

24. Börjesson PK, Jauw YW, de Bree R, et al. Radiation dosimetry of ${ }^{89} \mathrm{Zr}$-labeled chimeric monoclonal antibody U36 as used for immuno-PET in head and neck cancer patients. J Nucl Med. 2009;50:1828-1836. 